\title{
EVALUASI REAKSI TINGKAT KEPUASAN PESERTA DIKLAT MEMBATIK DI SANGGAR BATIK CIKADU TANJUNG LESUNG
}

\author{
Minhatul Ma'arif ${ }^{1}$, Rizal Fauzi ${ }^{2}$, Irma Murti Kusuma Anggara ${ }^{3}$ \\ ${ }^{1}$ STKIP Syekh Manshur, Pandeglang, Indonesia \\ ${ }^{2,3}$ Universitas Primagraha, Serang, Indonesia \\ Imaarifminhatul@gmail.com, ${ }^{2}$ sayarizalfauzi@gmail.com, ${ }^{3}$ irmamurtikusumaa@gmail.com
}

\begin{abstract}
ABSTRAK
Penelitian ini bertujuan untuk mengevaluasi reaksi dari tingkat kepuasan mahasiswa Pg-PAUD STKIP Syekh Manshur terhadap program diklat yang diselenggarakan oleh Sanggar Batik Cikadu Tanjung Lesung. Pendekatan ini menggunakan pendekatan kualitatif dengan mengadopsi model evaluasi Kirkpatrick pada level ke-1. Responden pada penelitian ini berjumlah 25 orang yang terdidi dari mahasiswa yang telah mengikuti Diklat membatik. Hasil penelitian didapat $60 \%$ mahasiswa tidak puas terhadap materi yang diberikan, $40 \%$ mahasiswa tidak puas terhdap penyelenggaran materi karena keterlambatan waktu pelaksanaan, seluruh mahasiswa merasa puas terhadap sarana dan prasarana diklat dan seluruh mahasiswa merasa puas terhadap kinerja instruktur. Dengan begitu dapat disimpulkan bahwa meskipun instruktur batik memiliki kemampuan yang handal dalam memfasilitasi belajar mahasiswa serta sarana prasarana yang diberikan sangat menunjang penyelenggaraan diklat akan tetapi tidak mampu mengatasi permasalahan belajar mahasiswa karena materi yang disajikan tidak sesuai dengan kebutuhan peserta diklat. Padahal, diklat membatik melalui seni membatik diharapkan mampu menjembati permasalahan mahasiswa pada mata kuliah kreativitas dan keberbakatan agar dapat membangun kreativitas dan bakat mahasiswa pada seni membatik. Sayangnya, mahasiswa pg-PAUD STKIP Syekh Manshur tidak begitu menyukai seni membatik sehingga hasil angket yang didapat menunjukkan bahwa hanya $40 \%$ mahasiswa yang tertarik dengan seni membatik.
\end{abstract}

Kata Kunci: diklat, evaluasi, batik

\section{EVALUATING THE REACTION OF THE PARTICIPANTS' SATISFACTION LEVEL ON BATIK TRAINING AT SANGGAR BATIK CIKADU TANJUNG LESUNG}

\begin{abstract}
This study aimed to evaluate the reaction of PG-PAUD students' satisfaction level to the training program organized by Sanggar Batik Cikadu Tanjung Lesung. This approach used a qualitative approach by adopting kirkpatrick evaluation model at level 1. Respondents to this study were 25 people who had participated in the training. The results of the study obtained that $60 \%$ of students dissatisfied with the material provided, $40 \%$ of students were dissatisfied with the implementation of the material due to delays in implementation time, all students were satisfied with the facilities and infrastructure of the training and all students were satisfied with the performance of the instructor. Thus, this study concluded that although batik instructors had a reliable ability in facilitating student learning and the infrastructure facilities provided greatly support the implementation of training but they were not able to overcome students' learning problems because the material presented was not in accordance with the needs of the participants of the training. In fact, the training through the art of batik was expected to be able to bridge students' problems in creativity and blessing courses in order to build creativity and talent of students in the art of batik. Unfortunately, student did not like the art of polishing so that the results of the questionnaire obtained showed that only $40 \%$ of students were interested in the art of painting.
\end{abstract}

Keywords: training, evaluation, batik

\begin{tabular}{|c|c|c|}
\hline Submitted & Accepted & Published \\
\hline 15 September 2021 & 12 November 2021 & 27 November 2021 \\
\hline
\end{tabular}

\begin{tabular}{|l|c|c|}
\hline Citation & $:$ & $\begin{array}{r}\text { Ma'arif, M., Fauzi, R., \& Anggara, I.M.K. (2021). Evaluasi Reaksi Tingkat Kepuasan Peserta Diklat Membatik Di Sanggar } \\
\text { Batik Cikadu Tanjung Lesung. Jurnal PAJAR (Pendidikan dan Pengajaran), 5(6), 1781-1788. DOI : } \\
\text { http://dx.doi.org/10.33578/pjr.v5i6.8563. }\end{array}$ \\
\hline
\end{tabular}

\section{PENDAHULUAN}

Pendidikan dan pelatihan (diklat) merupakan kegiatan yang banyak diselenggarakan oleh intansi atau lembaga untuk peningkatan kinerja. Tujuannya, agar peserta diklat mendapatkan pengetahuan dan keterampilan

untuk mempermudah bidang keahlian yang ditekuninya. Berdasarkan hasil analisis bibliometric menggunakan situs seforra.com didapat 362 artikel yang membahas terkait diklat pada September 2018 - Agustus 2021. Publikadi 
terkait diklat di Indonesia pada September 2020 Agustus 2021 mengalami penurunan yang sangat drastis akibat adanya pandemi covid-19 yaitu hanya 74 artikel. Padahal, pada September 2018 Agustus 2019 jumlah publikasi mencapai 154 artikel. Meskipun ditahun ini jumlah publikasi sangat sedikit, faktanya masih banyak lembaga yang menyelenggarakan diklat karena adanya kebutuhan di lapangan seperti di STKIP Syekh Manshur.

Tabel 1. Jumlah Publikasi Artikel Terkait Diklat Pada Tahun 2019-2021

\begin{tabular}{|c|c|}
\hline Tahun & Jumlah Publikasi \\
\hline September 2018 - Agustus 2019 & 154 \\
\hline September 2019 - Agustus 2020 & 134 \\
\hline September 2020 - Agustus 2021 & 74 \\
\hline Total & 362 \\
\hline
\end{tabular}

Diklat diselenggarakan oleh STKIP Syekh Manshur pada Program Studi PG-PAUD bekerjasama dengan Sanggar Batik Cikadu Tanjung Lesung untuk memfasilitasi belajar peserta didik. Diklat membatik diselenggarakan secara bertahap dengan jumlah peserta yang dibatasi. Diklat membatik diyakini akan mampu memfasilitasi kreativitas peserta didik dalam mengimplementasikan mata kuliah kreativitas dan keberbakatan ditengah pandemi covid-19. Selain itu, diklat juga dapat meningkatkan kemampuan peserta didik dalam bekerjasama pada kegiatan kelompok (Sjolie, Stromme, \& Boks-Vlemmix, 2021). Hanya saja, untuk mengetahui apakah diklat yang diselenggarakan mampu menjembatani permasalahan yang dihadapi perlu adanya evaluasi. Evaluasi merupakan serangkaian kegiatan yang dilakukan untuk mengukur tingkat keberhasilan dari suatu program (Cahapay, 2021).

Evaluasi yang dilakukan pada penelitian ini berupa evaluasi terbatas yang hanya berfokus pada evaluasi materi untuk mengetahui apakah materi yang disajikan sudah sesuai atau belum dengan kebutuhan peserta didik untuk meningkatkan kreativitas dan keberbakatan peserta didik di lapangan. Untuk evaluasi keseluruhan akan dilaksanakan setelah seluruh program berakhir. Maka, evaluasi terbatas yang diperlukan berupa evaluasi level 1 pada model evaluasi Kirkpatrick yang mengukur reaksi peserta didik terhadap diklat membatik yang diselenggarakan oleh Sanggar Batik Cikadu Tanjung Lesung. Reaksi perlu dilakukan dengan tujuan sebagai alat ukur bagi penyelenggara diklat terhadap kegiatan yang telah dilaksanakan dan dapat dijadikan referensi untuk kegiatan yang akan datang. Selain itu, reaksi juga perlu dilakukan untuk mengukur tingkat efektivitas keberhasilan dari program yang dijalankan (Shodiq, 2021) serta mengukur tingkat kepuasan peserta diklat (Khairi, 2021).

Penelitian ini bertujuan untuk mengevaluasi reaksi dari tingkat kepuasan mahasiswa PG-PAUD STKIP Syekh Manshur terhadap program diklat yang diselenggarakan oleh Sanggar Batik Cikadu Tanjung Lesung. Evalusi tersebut penting dilakukan agar antara capaian pembelajaran dengan program diklat dapat diukur kesesuaiannya. Diklat membatik diselenggarakan untuk menjembatani permasalahan pada Prodi Pg-PAUD pada mata kuliah kreativitas dan keberbakatan yang memerlukan alternative untuk meningkatkan kreativitas mahasiswa. Dengan begitu, diklat membatik diharapkan mampu meningkatkan kreativitas mahasiswa melaui seni membatik.

\section{KAJIAN TEORETIS}

Pendidikan dan Pelatihan (diklat) merupakan rangkaian proses pendidikan yang didalamnya terdapat pembelajaran juga pelatihan keahlian yang disesuaikan dengan kebutuhan. Di Indonesia, diklat banyak diselenggarakan oleh lembaga-lembaga nonformal bekerjasama dengan lembaga formal. Dengan begitu, terdapat banyak penelitian yang membahas terkait diklat yang diselenggarakan oleh lembaga-lembaga tertentu untuk memfasilitasi kebutuhan dilapangan karena diklat diyakini dapat meningkatkan pengetahuan dan juga kreativitas (Savul, Ikram, Khan, \& Khan, 2021). Hal tersebut terjadi dikarenakan didalam prosesnya terdapat pelatihan yang akan 
menstimulus peningkatan kemampuan peserta diklat. Selain itu, diklat juga diyakini mampu meningkatkan keterampilan serta meminimalisir kesalahan dalam interpretasi pengetahuan kedalam tindakan (Siebert, Kunz, \& Rolf, 2021). Keberhasilan program diklat meliputi beberapa factor seperti lingkungan pelatihan, peran instruktur, orientasi praktis dan kegunaan diklat (Sahni, 2020). Diklat membatik berbeda dengan diklat lainnya. Pada diklat membatik, peserta dituntut agar dapat memahami materi terkait sejarah batik, tata cara membatik, alat-alat membatik serta kearifan lokal disekitar tempat tinggal peserta diklat untuk dapat dituangkan kedalam kain batik. Selain itu, pada diklat membaatik peserta juga dituntut untuk dapat membuat karya batik berdasarkan pemahaman pada saat pemberian materi. Untuk itu, pemahaman dan penguasaan materi sangat menentukan terhadap interpretasi peserta diklat dalam membatik. Seluruh kegiatan membatik dilaksanakan menggunakan model direct instruction. Model direct instruction merupakan medel yang telah lama diadopsi oleh Sanggar Batik Cikadu (Ma'arif, Fauziah, \& Fauzi, 2020) karena mudah untuk diaplikasikan.

Diklat membatik yang diselenggarakan oleh Sanggar Batik Cikadu Tanjung Lesung diharapkan mampu mengatasi masalah pembelajaran pada mata kuliah kreativitas dan keberbakatan. Melalui diklat membatik peserta diajarkan membuat karya beradasarkan hasil analisis kearifan lokal dilingkungan tempat tinggal mahasiswa. Dengan begitu, akan meningkatkan kreativitas peserta diklat dalam membuat karya batik. Meskipun demikian, semua itu harus tetap dievaluasi agar antara ekpektasi dapat sesuai dengan realita di lapangan. Untuk itu, perlu dilakukan evaluasi diklat. Evaluasi diklat digunakan untuk mengukur keberhasilan dari program diklat yang telah diselenggarakan
(Iskandar et al., 2020; Purnomo \& Wulandari, 2019). Dengan begitu, penyelenggara akan mudah menentukan kercapaian dari program yang telah dilaksanakan. Terdapat beberapa cara dalam melaksanakan evaluasi diklat, akan tetapi evaluasi model Kirkpatrick yang paling umum digunakan karena mampu mengevaluasi mulai dari level terendah (level 1) hingga level tertinggi (level 4). Pada penelitian ini, peneliti hanya focus pada level1 yaitu mengevaluasi reaksi dari tingkat kepuasan peserta diklat.

\section{METODE PENELITIAN}

Penelitian ini dilaksanakan di Sanggar Batik Cikadu Tajung Lesung Pandeglang menggunakan pendekatan kualitatif dengan model Kirkpatrick. Responden pada penelitian ini berjumlah 25 orang yang terdiri dari mahasiswa Program Studi PG-PAUD STKIP Syekh Manshur yang telah mengikuti program Diklat membatik. Penelitian level-1 ini dilaksanakan pada bulan Agustus 2021. Hingga data level-1 dianalisis, peneliti masih melakukan evaluasi level-2, level-3 dan level-4. Data didapat melalui wawancara, observasi dan pengisian kuisioner yang telah dipersiapkan oleh peneliti. Intrument yang digunakan pada penelitian ini diadopsi dari level-1 pada model evaluasi Kirkpatrick yaitu reaction. Untuk mengetahui reaksi kepuasan peserta diklat maka perlu mengevaluasi materi yang telah diberikan, bentuk penyelenggaraan, sarana diklat dan kemampuan pemateri dalam menyampaikan program (Kirkpatrick \& Kirkpatrick, 2007). Dengan begitu, peneliti mengadopsi level pertama pada model evaluasi Kirkpatrick. Seluruh data yang dihasilkan pada penelitian ini telah divalidasi dan telah melalui triangulasi data agar seluruh data yang didapat sesuai dengan keadaan sebenarnya. Berikut adalah instrument yang digunakan untuk mengetahui tingkat kepuasan peserta diklat berdasarkan model evaluasi Kirkpatrick level-1:

Tabel 2. Kuesioner Kepuasan Mahasiswa Terhadap Diklat Membatik

\begin{tabular}{lll}
\hline \multicolumn{1}{c}{ Indikator } & \multicolumn{1}{c}{ Item } \\
\hline Materi & 1. & Kontribusi pemateri dalam peningkatan pengetahuan dan \\
& 2. & Kawasan \\
3. & Kesesuain materi dengan tujuan pelatihan \\
4. & Kualiatas isi materi \\
5. & Kejelasan materi untuk difahami
\end{tabular}


Jurnal PAJAR (Pendidikan dan Pengajaran)

Volume 5 Nomor 6 November | ISSN Cetak : 2580 - 8435| | ISSN Online : 2614 - 1337

DOI : http://dx.doi.org/10.33578/pjr.v5i6.8563

$\begin{array}{ll}\text { Penyelenggaraan } & \text { 1. elemen kesesuaian pemberian materi dengan jadwal yang telah } \\ & \text { 2. } \text { ditetapkan } \\ \text { 3. ketepatan waktu dalam pelaksanaan pelatihan } \\ \text { 4. kesigapan panitia dalam membantu peserta pelatihan } \\ \text { 1. kualitas sarana pelatihan } \\ \text { 2. alat peraga } \\ \text { 3. kesesuaian alat peraga } \\ \text { 4. konsumsi } \\ \text { 5. seminar kit } \\ \text { 6. fasilitas ruangan } \\ \text { 1. penguasaan materi } \\ \text { instruktur } & \text { 2. teknik penyampaian } \\ \text { 3. cara menjawab pertanyaan } \\ \text { 4. bahasa yang digunakan } \\ \text { 5. gesture (gerakan tubuh) } \\ \text { 6. mimik muka } \\ \text { 7. intonasi dan kecepatan berbicara. }\end{array}$

Seluruh kueioner yang dibuat, peneliti sebar kepada peserta pelatihan menggunakan google form. Untuk mendapatkan data terkait kesesuaian materi dengan tujuan pelatihan serta kualiatas sarana dan prasarana peneliti dapatkan melalui observasi langsung ke lapangan. Untuk kemampuan instruktur, peneliti dapatkan melalui wawancara langsung pada penyelenggara dan peserta pelatihan.

\section{HASIL DAN PEMBAHASAN}

Berdasarkan hasil analisis data, didapat bahwa untuk mengevaluasi reaksi tingkat kepuasan peserta diklat dengan mengadopsi level1 dari evaluasi Kirkpatrick melibatkan 5 (lima) unsur yaitu evaluasi materi yang diberikan, evaluasi penyelenggaraan, evaluasi sarana serta evaluasi kemampuan instruktur. Berikut adalah hasil analsis data dari evaluasi reaksi:

\section{1) Materi}

Berdasarkan evaluasi materi yang dilakukan oleh peneliti didapat :

Tabel 3. Presentase Materi Diklat Membatik

\begin{tabular}{llcccc}
\hline NO & \multicolumn{1}{c}{ INSTRUMEN } & $\begin{array}{c}\text { SANGAT } \\
\text { BAIK }\end{array}$ & BAIK & $\begin{array}{c}\text { CUKUP } \\
\text { BAIK }\end{array}$ & $\begin{array}{c}\text { KURANG } \\
\text { BAIK }\end{array}$ \\
\hline 1 & $\begin{array}{l}\text { Kontrubusi materi dalam peningkatan } \\
\text { pengetahuan dan wawasan }\end{array}$ & $72 \%$ & $15 \%$ & $8 \%$ & $5 \%$ \\
2 & $\begin{array}{l}\text { Kesesuaian materi dengan tujuan } \\
\text { pelatihan }\end{array}$ & $2 \%$ & $43 \%$ & $46 \%$ & $9 \%$ \\
3 & Kesesuaian materi dengan kebutuhan & $15 \%$ & $36 \%$ & $9 \%$ & $40 \%$ \\
4 & Kualitas isi materi & $18 \%$ & $33 \%$ & $44 \%$ & $1 \%$ \\
5 & Kejelasan materi untuk difahami & $80 \%$ & $11 \%$ & $9 \%$ & $0 \%$ \\
& $\quad$ TOTAL & $188 \%$ & $138 \%$ & $119 \%$ & $55 \%$ \\
\hline
\end{tabular}

Berdasarkan tabel di atas dapat dipahami bahwa presentase materi diklat membatik pada kategori sangat baik mencapai 188\%, baik 138\%, cukup baik $119 \%$ dan kurang baik $45 \%$. Dari seluruh pernyataan, peresentasi tertinggi terdapat pada kejelasan materi untuk difahami sebanayak $80 \%$. Itu berarti, materi yang disajikan dapat dimengerti dengan baik oleh peseta diklat, 
begitupun dengan kontribusi materi dalam peningkatan pengetahuan dan wawasan yang mencapai $72 \%$. Meskipun peserta diklat puas terhadap materi yang disajikan akan tetapi terdapat presentase kurang baik dengan angka yang tinggi pada kesesuain materi dengan kebutuhan yaitu $40 \%$. Itu beararti, materi yang diberikan oleh penyelenggara tidak sesuai dengan kebutuhan peserta diklat. Akibatnya, berdasarkan hasil wawancara didapat $52 \%$ peserta diklat tidak mengikuti materi dengan fokos karena meresa tidak sesuai dengan kebutuhan dilapangan.

\section{2) Penyelenggaraan}

Setelah mengevaluasi materi, tahap selanjutnya yaitu evaluasi penyelenggaraan. Berikut adalah hasil analisis data yang telah diolah oleh peneliti:

Tabel 4. Presentase Evaluasi Penyelenggaraan Diklat Membatik

\begin{tabular}{llcccc}
\hline NO & \multicolumn{1}{c}{ INSTRUMEN } & $\begin{array}{c}\text { SANGAT } \\
\text { BAIK }\end{array}$ & BAIK & $\begin{array}{c}\text { CUKUP } \\
\text { BAIK }\end{array}$ & $\begin{array}{c}\text { KURANG } \\
\text { BAIK }\end{array}$ \\
\hline 1 & $\begin{array}{l}\text { Elemen kesesuaian pemberian materi } \\
\text { dengan jadwal yang telah ditetapkan }\end{array}$ & $45 \%$ & $33 \%$ & $22 \%$ & $0 \%$ \\
2 & $\begin{array}{l}\text { Ketepatan waktu dalam pelaksanaan } \\
\text { pelatihan }\end{array}$ & $0 \%$ & $18 \%$ & $22 \%$ & $60 \%$ \\
3 & $\begin{array}{l}\text { Kesediaan panitia dalam membantu } \\
\text { peserta pelatihan }\end{array}$ & $80 \%$ & $17 \%$ & $3 \%$ & $0 \%$ \\
4 & $\begin{array}{l}\text { Kesigapan panitia dalam membantu } \\
\text { peserta pelatihan }\end{array}$ & $87 \%$ & $8 \%$ & $4 \%$ & $1 \%$ \\
\hline
\end{tabular}

Berdasarkan tabel diatas dapat dipahami bahwa pada proses penyelenggaraan diklat, peserta diklat merasa sangat puas terhadap kesediaan dan kesigapan panitia dalam membantu peserta pelatihan. Hal tersebut dapat dibuktikan melalui table presentase di atas pada kesediaan panitia dalam membantu peserta diklat sebesar $80 \%$ dan kesigapan panitia dalam membantu peserta pelatihan $87 \%$. Keduanya merupakan angka tertinggi pada evalusi penyelenggaraan. Meskipun demikian, peserta diklat juga mengeluhkan adanya keterlambatan dalam pelaksanaan diklat. Kekecewaan tersebut dibuktikan melalui analisis angket pada sekala kurang baik mencapai $60 \%$. Angka tersebut sangat tinggi diantara presentase kurang baik lainnya.

Oleh karen itu, perlu dilakukan evaluasi lebih lanjut mengapa penyelenggara diklat tidak melaksanakannya tepat waktu. Menurut data hasil wawancara peneliti dengan penyelenggara diklat, keterlambatan waktu tersebut dikarenakan kendala oprasional mulai dari infokus yan tidak berfungsi, adanya pemadaman listrik saat pelatihan serta keterlambatan kedatangan pemateri. Dengan begitu, dapat peneliti simpulkan bahwa ketidak puasan peserta diklat pada evalusi penyelenggaraan terletak pada ketepatan waktu yang terkendala pemadaman listrik dan keterlambatan kedatangan pemateri tamu.

3) Sarana

Setelah melakukan evaluasi materi dan evalusi penyelenggaraan tahap selanjutnya untuk mendapatkan kesimpulan terkait reaksi pada tingkat kepuasan mahasiswa terhdap diklat membatik yaitu evaluasi sarana.

Tabel 5. Presentase Evaluasi Sarana Diklat Membatik

\begin{tabular}{llcccc}
\hline \multirow{2}{*}{ NO } & \multicolumn{1}{c}{ INSTRUMEN } & SANGAT & \multirow{2}{*}{ BAIK } & CUKUP & KURANG \\
& & BAIK & & BAIK \\
\hline 1 & Kualitas sarana pelatihan & $31 \%$ & $43 \%$ & $24 \%$ & $2 \%$ \\
2 & Alat peraga & $21 \%$ & $60 \%$ & $15 \%$ & $4 \%$ \\
3 & Akesesuaian alat peraga & $19 \%$ & $80 \%$ & $1 \%$ & $0 \%$ \\
4 & Kualitas sarana pelatihan & $0 \%$ & $79 \%$ & $21 \%$ & $0 \%$ \\
\hline
\end{tabular}


Jurnal PAJAR (Pendidikan dan Pengajaran)

Volume 5 Nomor 6 November | ISSN Cetak : 2580 - 8435| | ISSN Online : 2614 - 1337

DOI : http://dx.doi.org/10.33578/pjr.v5i6.8563

\begin{tabular}{|c|c|c|c|c|c|c|}
\hline 5 & Konsumsi & & $12 \%$ & $11 \%$ & $74 \%$ & $3 \%$ \\
\hline 6 & Seminar kit & & $22 \%$ & $29 \%$ & $46 \%$ & $3 \%$ \\
\hline 7 & Fasilitas ruangan & & $18 \%$ & $50 \%$ & $30 \%$ & $2 \%$ \\
\hline & & TOTAL & $123 \%$ & $352 \%$ & $211 \%$ & $14 \%$ \\
\hline
\end{tabular}

Berdasarkan hasil analisis data didapat bahwa kualitas sarana pelatihan memuaskan karena seluruh data berada pada angka yang stabil. Begitupun dengan alat peraga, kesusuaian alat peraga, kualitas sarana pelatihan, konsumsi, seminar kit dan fasilitas ruangan. Dengan demikian dapat ditarik kesimpulan bahwa sarana dan prasarana pada diklat membatik sudah sangat memuaskan karena sesuai dengan kebutuhan peserta diklat.

\section{4) Kemampuan instruktur}

Tabel 6. Presentase Kemampuan Instruktur Diklat Membatik

\begin{tabular}{|c|c|c|c|c|c|}
\hline NO & INSTRUMEN & $\begin{array}{l}\text { SANGAT } \\
\text { BAIK }\end{array}$ & BAIK & $\begin{array}{l}\text { CUKUP } \\
\text { BAIK }\end{array}$ & $\begin{array}{c}\text { KURANG } \\
\text { BAIK }\end{array}$ \\
\hline 1 & Penguasaan materi & $3 \%$ & $62 \%$ & $29 \%$ & $6 \%$ \\
\hline 2 & Teknik penyampaian & $2 \%$ & $29 \%$ & $65 \%$ & $4 \%$ \\
\hline 3 & Cara menjawab pertanyaan & $12 \%$ & $46 \%$ & $40 \%$ & $2 \%$ \\
\hline 4 & Bahasa yang digunakan & $2 \%$ & $79 \%$ & $19 \%$ & $0 \%$ \\
\hline 5 & Gesture (gerakan tubuh) & $9 \%$ & $12 \%$ & $79 \%$ & $0 \%$ \\
\hline 6 & Mimik muka & $20 \%$ & $30 \%$ & $49 \%$ & $1 \%$ \\
\hline 7 & $\begin{array}{l}\text { Intonasi dan kecepatan berbicara. } \\
\text { TOTAL }\end{array}$ & $\begin{array}{c}3 \% \\
48 \%\end{array}$ & $\begin{array}{c}62 \% \\
320 \%\end{array}$ & $\begin{array}{c}29 \% \\
310 \%\end{array}$ & $\begin{array}{c}6 \% \\
19 \%\end{array}$ \\
\hline
\end{tabular}

Berdasarkan data di atas dapat disimpulkan bahwa instrukur menguasasi materi dengan baik, hal tersebut dibuktikan dengan jumlah presentase sebesar $62 \%$. Kemudian, presentase tertinggi ada pada bahasa yang digunakan. Semua itu terjadi karena instruktur batik pada diklat yang diselenggarakan sudah mengajar batik cukup lama yaitu 6 tahun. Maka, tak heran jika bahasa yang digunakan, gesture, mimik muka, intonasi, tehnik penyampaian serta cara menjawabnya sangat baik, baik dan cukup baik. Karena instruktur sudah sangat berpengalaman dalam menyampaikan materi.

Sehingga, pelaksanaan diklat membatik memiliki reaksi yang beragam dari peserta diklat yaitu mahasiswa Pg-PAUD. Hal tersebut dapat dibuktikan dengan jumlah presentasi yang beragam pada tiap indikator akngket yang disebar. Pada materi, terdapat 60\% mahasiswa yang beranggapan bahwa materi tidak sesuai dengan kebutuhan mereka di lapangan. Akan tetapi untuk item lainnya seperti kejelasan materi, kesesuai dengan tujuan pelatihan serta kulitas materi berada pada kategoti memuaskan. 2) evaluasi penyelenggaraan diklat, pada kategori ini terdapat angka presentase ketidak puasan yang tinggi karena keterlambatan penyampaian materi dari jadwal yang telah ditetapkan dengan presentase sebesar $60 \%$. Angka tersebut merupakan angka ketidak puasan tertinggi dari seluruh indikator yang ada pada evaluasi penyelenggaraan. Meskipun angka presentase lainnya memuaskan, akan tetapi tertutup oleh ketidak puasan akibat keterlambatan waktu pelaksanaan. 3) evaluasi sarana, berdasarkan hasil analisis dapat disimpulkan bahwa Sanggar Batik Cikadu memiliki sarana yang sangat memadai untuk mneyelenggarakan diklat membatik karena mampu mengakomodir seluruh kebutuhan peserta diklat. 4) evaluasi kemampuan instruktur, pada indikator ini peserta diklat merasa sangat puas karena instruktur yang melatih sudah sangat berpengalaman, dengan begitu peserta diklat dapat terpenuhi seluruh kebutuhannya selama diklat berlangsung. Instruktur juga dinilai sangat sigap dalam membantu peserta diklat. 


\section{SIMPULAN DAN REKOMENDASI}

Berdasarkan hasil evaluasi level-1 model Kirkpatrick pada evaluasi reaksi tingkat kepuasan peserta diklat membatik dapat disimpulkan bahwa meskipun instruktur batik memiliki kemampuan yang handal dalam memfasilitasi belajar mahasiswa serta sarana prasarana yang diberikan sangat menunjang penyelenggaraan diklat akan tetapi tidak mampu mengatasi permasalahan belajar mahasiswa karena materi yang disajikan tidak sesuai dengan kebutuhan peserta diklat. Padahal, diklat membatik melalui seni membatik diharapkan mampu menjembati permasalahan mahasiswa pada mata kuliah kreativitas dan keberbakatan agar dapat membangun kreativitas dan bakat mahasiswa pada seni membatik. Sayangnya, mahasiswa pg-PAUD STKIP Syekh Manshur tidak begitu menyukai seni membatik sehingga hasil angket yang didapat menunjukkan bahwa hanya $40 \%$ mahasiswa yang tertarik dengan seni membatik.

Rekomendasi peneliti untuk kegiatan diklat membatik yang akan datang, agar penyelenggara diklat yaitu Sanggar Batik Cikadu mampu menyesuaikan materi dengan kebutuhan peserta diklat secara maksimal. Selanjutnya, sanggar batik cikadu juga harus menyiapkan halhal insidential yang mungkin terjadi seprti, adanya pemadaman listrik yang mengganggu berlangsungnya kegiatan karena tidak dapat menampilkan video. Dengan begitu, perlu ada kesiapan khusus jika terjadi hal-hal yang tidak diinginkan.

\section{DAFTAR PUSTAKA}

Cahapay, M. (2021). Kirkpatrick Model: Its Limitations as Used in Higher Education Evaluation. International Journal of Assessment Tools in Education, 8(1), 135144. https://doi.org/10.21449/ijate.856143

Iskandar, A., Subekan, A., Diklat, B., Makassar, K., Anggaran, P., \& Keuangan, P. (2020). Evaluating the Distance Learning in the Pandemic Era: A Case Study at Financial Education and Training Agency Makassar. Jurnal PAJAR ( Pendidikan Dan Pengajaran ), 4(6), 1206-1221.
Khairi, M. Y. (2021). Evaluasi Learning Penyelenggaraan Pelatihan Jarak Jauh Tata Naskah Dinas Kantor Kementerian Agama Kabupaten Kapuas Oleh Balai Diklat Keagamaan Banjarmasin, 5(2), 151-160.

Kirkpatrick, D. L., \& Kirkpatrick, D. J. (2007). Implementing the Four Levels: San Francisco, California: Berrett-Koehler Publishers, Inc.

Ma'arif, M., Fauziah, M., \& Fauzi, R. (2020). Effectiveness of Direct Instruction For Learning Models Improving Batik Skills in Basic School Students in Sanggar Batik Cikadu. JURNAL PAJAR (Pendidikan Dan Pengajaran), 4(1), 151-158. https://doi.org/http://dx.doi.org/10.33578/ pjr.v4i1.7894

Maarif, M., \& Fauzi, R. (2018). Effectiveness of Field Trip Learning Towards Batik Banten Curriculum in Elementary School, 1(2), 41-45.

Purnomo, H., \& Wulandari, I. (2019). Pengembangan Bahan Ajar Evaluasi Pembelajaran Untuk Pendidikan Guru Sekolah Dasar Universitas Kuningan. JURNAL PAJAR (Pendidikan Dan Pengajaran), 3(6), 1204. https://doi.org/10.33578/pjr.v3i6.7878

Sahni, J. (2020). Managerial training effectiveness: An assessment through Kirkpatrick framework. TEM Journal, 9(3), 12271233. https://doi.org/10.18421/TEM93-51

Savul, S., Ikram, A., Khan, M. A., \& Khan, M. A. (2021). Evaluation of Infection Prevention and Control Training Workshops Using Kirkpatrick'S Model. International Journal of Infectious Diseases, 0-19. https://doi.org/10.1016/j.jijid.2021.09.005

Shodiq, M. (2021). Evaluasi Reakasi dan Pengetahuan Peserta Terhadap Mata Pelatihan Etika Publik. MANAJERIAL: Jurnal Inovasi Manajemen Dan Supervisi Pendidikan, 1(1), 25-32.

Siebert, J. U., Kunz, R. E., \& Rolf, P. (2021). Effects of decision training on individuals' decision-making proactivity. European Journal of Operational Research, 294(1), 264-282.

https://doi.org/10.1016/j.ejor.2021.01.010 
Jurnal PAJAR (Pendidikan dan Pengajaran)

Volume 5 Nomor 6 November | ISSN Cetak : 2580 - 8435| ISSN Online : 2614 - 1337

DOI : http://dx.doi.org/10.33578/pjr.v5i6.8563

Sjolie, E., Stromme, A., \& Boks-Vlemmix, J. (2021). Team-skills training and real-time facilitation as a means for developing student teachers' learning of collaboration. Teaching and Teacher Education, 107, 103477.

https://doi.org/10.1016/j.tate.2021.103477 